\title{
What is this thing called 'natural'? The nature-culture divide in climate change and biodiversity policy
}

\author{
Ylva Uggla ${ }^{1}$ \\ Örebro University, Sweden
}

\section{Introduction}

Sean Penn's Into the Wild is a magnificent, epic film that tells an intriguing story of the wilderness. The film, based on Jon Krakauer's book of the same title, is about a young man who leaves what he perceives to be false and materialistic life behind to enter the wild in search of the pure and authentic. In an interview about the film, Sean Penn said that, while human inauthenticity and corruption impede our quality of life, "the wilderness is relentlessly authentic" (MacGrath 2007). However, the young man's quest for the pristine and pure, and his revolt against society, end in misery and death. In this story, the wilderness represents both the untouched and pure, which are worth aiming for, and the untamed and violent, which threaten and destroy human lives.

This depiction of the wilderness illustrates humans' deeply ambivalent relationship with nature, which oscillates between romantic devotion to nature and attempts to conquer it. Likewise, it reflects modern society's nature-culture dualism, where nature is defined as "the other" vis-à-vis human society and culture. This notion is manifested in the relationship between humans and nature, whether it concerns human mastery of nature or humans as its keeper. Accordingly, the nature-culture divide permeates the underlying logic of international environmental regulation. In recent decades, environmental regulation has evolved to encompass a more holistic approach, representing a non-anthropocentric view (Emmenegger and Tscentscher 1994).

This paper treats two highly topical and interconnected environmental issues, climate change and biodiversity, that are regulated in concurrent international conventions. The Convention on Biological Diversity (CBD) embodies a holistic approach and articulates two values of biodiversity; nonanthropocentric, intrinsic value and anthropocentric, instrumental value. In contrast, the Framework Convention on Climate Change (UNFCCC) presents climate change entirely as a matter of human survival and welfare. Although the two conventions were introduced in the early 1990s, they differ in their view of, and expressed motives for, environmental protection. Yet, in considering what is worth protecting and/or why regulation is required, the CBD and the UNFCCC use "the natural" as a demarcation line.

Environmental regulation concerns not only how to direct a predefined reality or to govern specific objects, but it is also involved in constructing these entities. Explicitly or implicitly, regulation creates demarcations that make objects appear hazardous or harmless, important or unimportant, or natural or nonnatural (Lidskog et al. 2009: 3). Although the notion of protecting the natural may seem neutral or congenial, it is complex and deeply value-laden, and must be interpreted and defined when put into practice. All conceptions of the nature-culture divide involve designating boundaries, and help construct the relationship between humans and their environment. Instead of searching for nature and the natural, we should view these concepts as political, and analyze the implications of particular definitions and their applications (Swyngedouw 2007: 19-20).

The aim of the paper is to analyze how the natural and concerns for biodiversity and climate change are constructed in applicable regulatory frameworks. Furthermore, the paper explores the social and environmental consequences of these constructions. Analysis of the explicit and implicit assumptions underlying these constructions tells us how human agency and the relationship between humans and nature are defined, and how and to whom responsibility for environmental protection is assigned.

This paper comprises six sections, starting with this introduction. Section two provides a brief overview of the modern nature-culture divide and some of its implications for environmental protection. Section three discusses how the concepts of nature and culture are negotiated in relation to each other. Section four analyzes motives and arguments for biodiversity conservation and climate change mitigation. Section five analyzes how the "natural" is constructed in the regulatory framework and the social and environmental implications of this framing. Section 6 concludes that, although the "natural" is often used as a socially and politically neutral concept, the search for it remains a deeply value-laden activity that entails drawing boundaries and assigning priorities.

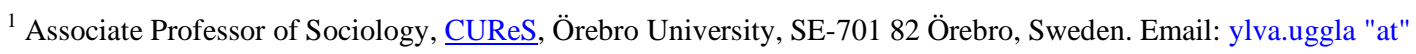
oru.se. Thankyou to the referees and editor.
} 


\section{The modern nature-culture divide and environmental protection}

The modern understanding of the relationship between humans and nature is ambiguous, encompassing a wide range of emotions and rationales for its exploitation, domination and preservation. Out of a tangle of events and ideas, the conception of nature emerged, as an object of scientific inquiry and as a resource for economic progress (i.e., resourcism, conservation for the sake of benefits that humans derive from nature). This way of relating to the environment has its roots in Europe, where an "ideology of conquest and domination towards nature has evolved", an ideology that permeates globally today (Pattberg 2007: 1). In this process, modernism has transformed wilderness into a nature devoid of intrinsic value (Oelschlaeger 1991).

One important precursor of this change was the Judeo-Christian ethic. The material world was God's gift to humans for them to master, but it needed improvement, achievable only by human intelligence and physical labor. The Judeo-Christian recovery story is by no means one-sided, as it also alludes to the stewardship of nature and human responsibility for God's creation (Egri 1999: $67 \mathrm{ff}$.; Merchant 2003: 85 ff.). In this tradition we find the origins of the conception of humankind as both nature's conqueror and its keeper. Another important social and intellectual transition that led to the transformation of "wilderness" to "nature" was the Enlightenment, which ushered in the scientific and industrial revolutions, and the emergence of capitalism. The metaphor of nature as mechanism or machine was established, and nature and its diverse resources (e.g., water, forests and minerals) became mere means to an end, that is, materials fueling consumption, progress and continuous economic growth (Oelschlaeger 1991: 93-95; cf. Merchant 2003: 83-84).

Modernism, however, has not unfolded without criticism and counter-argument, and nineteenth century romanticism represents one such counter-argument. One feature of romanticism, a diverse movement, is that it took an aesthetic turn and embraced the idea of self-fulfillment through a personal relationship with wild and pristine nature. Urban life, the city and civilization were viewed as distortions, whereas wild nature was idealized and praised for its beauty and splendor (Faarlund 1993: 163; Hay 2002: $5 \mathrm{ff}$.).

Since the nineteenth century, nature lovers, conservationists and the environmental movement have frequently raised their voices in criticism of the environmental consequences of urbanization and industrialization. The movement has taken various guises, ranging from the conservation movement to ecofeminism. Despite the differences between these lines of thought, the representation of nature as inherently good is predominant in environmental thinking (Gandy 2002:13). Likewise, the presumption is shared that modern humans are at the root of environmental degradation.

There are several ideological currents-such as biocentrism, ecocentrism and streams of ecofeminism that question human supremacy over nature and notions of nature as "other" to human society and culture. There are also visions that aspire to transcend the nature-culture divide: the possibility of "a new synthesis" and the notion of "the human project as taking place within rather than outside nature" (Oelschlaeger 1991: 317). However, these lines of thought have been far from prominent in contemporary environmental discourse.

Accounts of the relationship between humans and nature, as they appear in the history of ideas, convey ambiguous messages that identify humankind as both destroyer and rescuer, and wilderness or "natural nature" as both threat and refuge. The current, more or less hegemonic discourse of sustainable development unites a number of such diverse elements. Left out of this discourse, however, is a central element of the various guises of the "green critique", namely criticism of the notion of industrial progress itself (Hajer and Fischer 1999: 2). The discourse of sustainable development recognizes the structural character of environmental problems, but it also assumes that the institutions of modern society can deal with them. It promotes further, not less, modernization, responding to criticism of contemporary society with a modernistic answer involving research, technological innovation, market forces, and so on.

The discourse of sustainable development is based on the modern nature-culture divide and comprises an ambivalence towards nature and human agency that has been part of the relationship between humans and their environment for so long in the Western world. It is also within this discourse that the treaties of biodiversity and climate change are negotiated.

\section{Negotiating nature and culture}

The notions of nature and the natural, as distinct from culture and society and untouched by humans, can be questioned since we cannot find any site on earth that fits that description. As many scholars have convincingly argued, the idea of nature and culture as separate entities is flawed, and nature is better understood as "socio-environmental arrangements" (Swyngdouw 2007: 20), or "seeming nature" (Gandy 2002: 110). In the modern understanding of a strict division between culture and nature as separate categories, Bruno Latour (1993) claims that "we have never been modern", since our world is and always 
has been full of hybrids: socio-natural objects and subjects. Despite these insights, the separation of nature and culture is manifest in human thought and environmental policies.

The concepts of "nature" and the natural are familiar and yet highly elusive. On the one hand these terms are easily and frequently used; on the other they are difficult to grasp and define (Soper 1995; cf. Newton 2007). Contradictory thinking attaches a variety of meanings, values and functions to nature. Most commonly described is the resource and aesthetic value of the natural world. Nature is also enlisted in environmental protection. Nature can be used to complement technical solutions, for example as barrier and buffer in hazardous waste management (Uggla 2004). In this case, it is a sturdy and stable nature that compensates for human shortcomings.

Accordingly, there is not one nature, but a diversity of contested natures constituted through sociocultural processes from which they cannot be separated. Different conceptualizations of nature - as resource, as threatened, or sacred, pure, and stable - imply different responses to potential threats against these natures (Macnagthen and Urry 1998:23). Therefore, nature is an elastic concept, providing an ideological vehicle for almost any position on the relationship between humans and their environment (Gandy 2002:13).

The meaning of nature is continuously negotiated in relation to its supposed counterpart - human culture and society. In early sociology, in an effort to explain human consciousness and the mind, animals were frequently used to explain the uniqueness of humankind (Tuomivaara 2009: 49). It is in relation to animals and nature, defined as the other, that the uniqueness of humans and human character stands out. In this sense, nature serves to define what it means to be human.

Negotiating nature and culture - drawing boundaries that define the natural versus the non-natural defines and justifies certain actions. Humans do something to the world when they draw boundaries between nature and culture, between the natural and the non-natural, and between acceptable and unacceptable human interference in natural systems. Any understanding of nature involves an understanding of society, and of certain social choices. In this sense, nature also fulfills political functions, telling us how to live our lives.

\section{Loss of biodiversity and climate change: heading for disaster?}

Two highly topical international environmental regulatory frameworks concern climate change and biodiversity. The close connection between science and policy in these two areas implies a shift in the conceptual categories according to which people understand and value nature. Notably, notions of climate change and biodiversity entail an understanding of environmental protection as a shared, global concern (Miller and Edwards 2001: 6; Takacs 1996). Furthermore, these issues, which are presumed to be essential to human survival and welfare, are closely interconnected. First, biodiversity is thought to be important for strengthening ecosystem resilience and bolstering ecosystem adaptability to environmental variations such as climate change (CBD 2007; Glowka et.al. 1994: 9). Second, although changing conditions have continuously contributed to the rearrangement of biological systems, human-induced climate change is thought to amplify such variation, threatening to accelerate "the loss of biodiversity already under way due to other human stressors" (Hannah et al. 2005: 3). Accordingly, the link between biodiversity and climate change is understood as reciprocal, that is, human-induced climate change threatens biodiversity, while biodiversity itself can reduce the adverse impacts of climate change on people and production systems (CBD 2007; Lovejoy and Hannah 2005). But how are biodiversity conservation and climate change mitigation justified in the regulatory framework?

\section{Motives for biodiversity conservation}

The concept of biodiversity has an inclusive character promoted by members of both the conservation and scientific communities, representing a range of interests (Farnham 2007: 241 ff.). Tracing the roots of "biodiversity" reveals a deeply value-laden concept that subsumes several values - aesthetic, recreational, scientific, economic, and for life-support - that are related to various aspects of conservation, including wilderness protection, resourcism, and the protection of endangered species. Although several values of biodiversity have been emphasized, resourcism has been central to the biodiversity conservation discourse (Farnham 2007: 4 ff.; cf. Evans 2007: 244; cf. Escobar 1998). The biodiversity concept has a normative component: biodiversity is considered as something that is good for several reasons, implying that greater diversity entails greater value.

It is also apparent that human activity is believed to pose the main threat to rich biodiversity through, for example, habitat fragmentation, introducing alien species, and global climate change, all of which are treated as human-induced (anthropogenic) phenomena (Lovejoy 2005: 325; Binimelis et al. 2007). Fragmentation research has been mainly oriented towards human-induced disturbances and defined as an anthropogenic phenomenon that threatens a primordial state, which is characterized by uniform and extensive habitats conducive to rich biodiversity (Lovejoy 2005, p. 325; Evans 2007: 244). In line with this 
understanding, and in order to protect biodiversity, wild nature and coherent green areas are highlighted. Rich biodiversity is thus framed as a favorable state that is threatened by human agency.

Although value-laden and normative, the biodiversity concept is also closely connected to science and scientific values of nature, which have imbued the biodiversity concept with a sense of objectivity (Farnham, 2007: 4; cf. Evans 2007: 243). By subsuming a variety of values and interests, the concept has gathered together actors from a range of fields, including politicians, scientists and conservationists, making them allies sharing a cause (cf. Gieryn 1999; Takacs 1996) and a unified frame of reference.

Despite the unity of purpose associated with biodiversity concerns, the precise definition of biodiversity is by no means self-evident. As Escobar (1998: 53) explains, "although 'biodiversity' has concrete biophysical referents, it must be seen as a discursive invention of recent origin". However, a threetiered standard definition, including genetic, species and ecosystem diversity, has evolved (Farnham 2007: 13; 23 ff.). This definition was established by the CBD and adopted in 1992. It unites a variety of policy and scientific recommendations from groups such as the sustainable-use movement, farmer's rights movements, and bioprospectors, connecting biodiversity conservation to sustainable development (Farnham 2007: 26; CBD and UNEP 2004). The CBD (Fig. 1) refers to biodiversity as the variability among living organisms from all sources, and the Convention has been described as new and innovative because of its holistic approach.

It also introduces the notion of the intrinsic value of biodiversity (Glowka et al. 1994; Rehbinder 2002). In its preamble, in which the negotiating states set out their concerns and motives, the Convention presents the values of biodiversity and, for the first time in a binding international instrument, stresses these intrinsic values. An object with intrinsic value is something that is valuable for its own sake, independent of its usefulness to someone or something else. Referring to an object's intrinsic value often implies that this value inheres within the object, indicating that this value has some kind of external existence independent of human consciousness. The conclusion that something is valuable in itself may be interpreted in two ways. First, value in itself can be seen as self-contained, that is, it would be valuable even if there were nothing else in the world (cf. G. E. Moore's isolation test of intrinsic value). Second, value in itself can be seen as persistent, in other words, the value remains regardless of situation or context (Levinson 2004: 321322). The concept of intrinsic value is disputed. For example, whether it is only concrete entities (e.g., people) or states of existence (e.g., pleasures and desire satisfaction) that can have intrinsic value (Bradley 2006; see also Zimmerman 2001; Levinson 2004). Likewise, the intrinsic value of biodiversity as a whole is disputed, whether intrinsic value can be attributed to all of it or to specific components (Krishnamurthy 2003: 73).

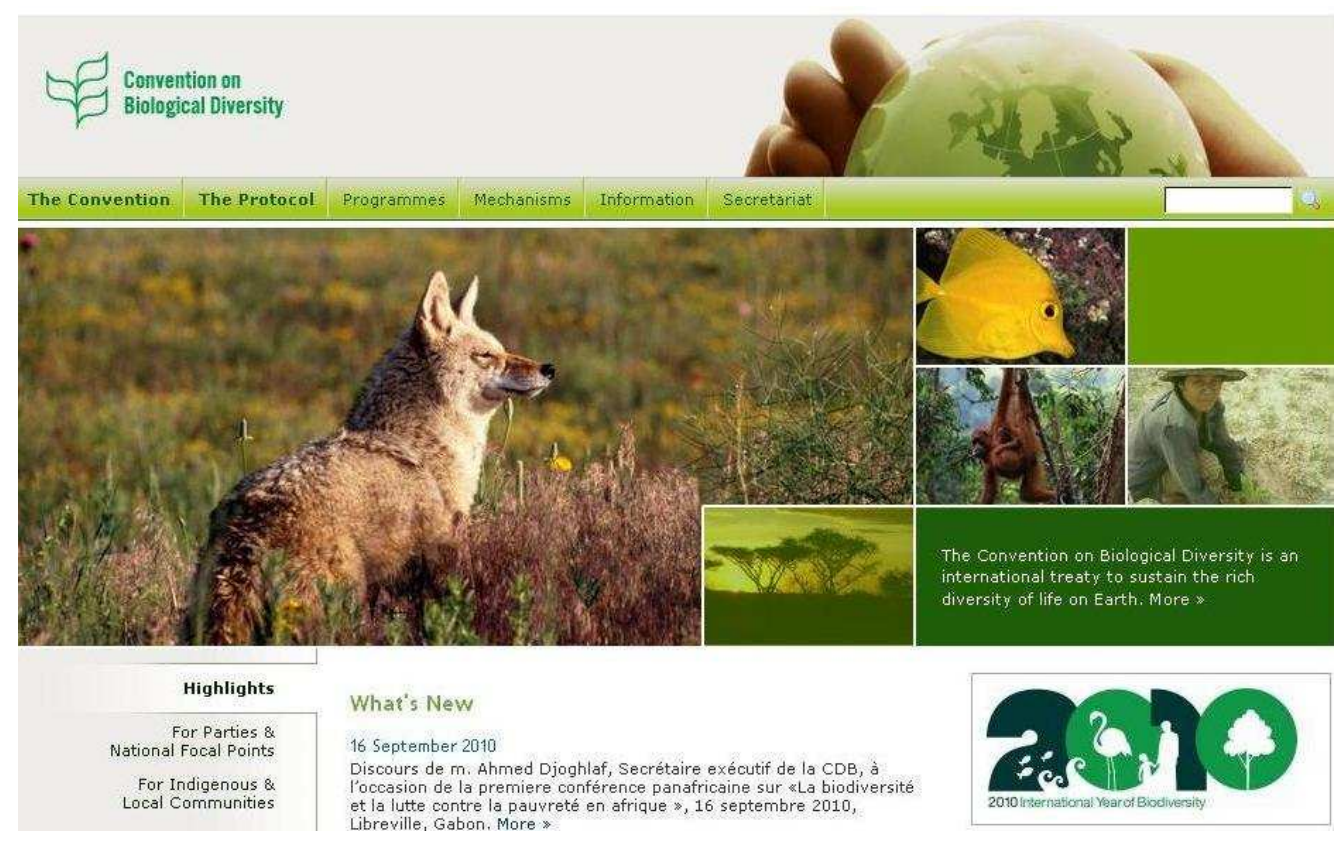

Fig. 1: Convention on Biodiversity website, http://www.cbd.int/

Neither the Convention nor the CBD handbook (Secretariat of the Convention on Biological Diversity 2005) ever defines how intrinsic value should be understood or what it implies. The inclusion of the concept of intrinsic value in environmental regulation, however, indicates a shift in environmental regulation towards acknowledging non-anthropocentric values (cf. Emmenegger and Tscentscher 1994). 
The first paragraph of the preamble to the CBD articulates the contracting parties' consciousness "of the intrinsic value of biological diversity and the ecological, genetic, social, economic, scientific, educational, cultural, recreational, and aesthetic values of biological diversity and its components." Here, the CBD emphasizes the inherent worth of biodiversity and draws a line between this intrinsic, nonanthropocentric value of biodiversity as a whole and other anthropocentric, instrumental values of biodiversity and its components (Holder and Lee 2007: 3).

The inclusion of the notion of intrinsic value indicates an alternate perception of nature, viewed against resourcism. Instead, citing the intrinsic value of biodiversity alludes to the perception of a sacrosanct nature, which represents pre-modern as well as postmodern interpretations of nature (Rientjes 2002: 7; cf. Merchant 2003: 192).

\section{Motives for climate change mitigation}

The theory of global warming as a consequence of greenhouse gas (GHG) emissions was raised several times in the twentieth century, but it was not until the 1980s that climate change became a serious political issue. The logic underlying the international community's concern for global climate change is based on climate modeling that indicates potential adverse effects-such as intensified droughts and floods, and rising sea level-due to human GHG emissions. Climate modeling is also the prerequisite for distinguishing between natural climate variability and human-induced climate change, since periods of frequent rainfall, little or no rainfall, or of extreme weather events cannot positively be attributed to anthropogenic climate change. As Edwards puts it:

The inherent variability of weather makes it impossible to attribute individual storms, floods, droughts or hurricanes to changes in the global climate. Only by coupling statistical analyses to climate modeling exercises have scientists been able to isolate and display the "fingerprint" of global warming in changing weather patterns around the world. (Edwards 2001: 33)

Today, there is a complex alliance between science-based descriptions of climate change and climate policy (Edwards 2001: 34). In this fusion of science and policy, the Intergovernmental Panel on Climate Change (IPCC), set up in 1988 to provide independent scientific advice on climate change, functions as a center of authority that must uphold its credibility in the eyes of both the scientific and policy communities (Edwards and Schneider 2001; cf. Adger 2006). The role of the IPCC is not to conduct research, but to assess "on a comprehensive, objective, open and transparent basis the scientific, technical and socio-economic information relevant to understanding the scientific basis of risk of human-induced climate change" (IPCC 1998: 1).

The IPCC summarizes and communicates its assessments to support policy-making, and its First Assessment Report, published in 1990, constituted the scientific basis of the United Nations Framework Convention on Climate Change (UNFCCC), adopted in 1992 (Fig. 2). The IPCC reports present the scientific consensus that the Earth's climate is being affected by human activities. The Assessment Reports are part of the scientific construct of the consensus, and this consensus has remained relatively stable over time about one key factor: the sensitivity of the climate to atmospheric $\mathrm{CO}_{2}$ doubling, expressed as a projected increase of global mean temperature (van der Sluijs 1998; cf. von Storch 2009).

The policy responses to climate change established in the UNFCCC are mitigation and adaptation. "Mitigation" concerns reducing GHG emissions, and enhancing and protecting greenhouse gas sinks and reservoirs such as forests and oceans. "Adaptation" concerns various human responses to experienced or expected consequences of climate change, such as flood control and crop adjustment. Although adaptation includes both moderating harm and exploiting beneficial opportunities, the international community's adoption of the UNFCCC is a sign of its great concern about the adverse effects of climate change. Likewise, although previous and present climate variation has resulted and may result in natural disasters such as droughts, floods, and landslides, the concern underlying mitigation is that anthropogenic climate change has contributed to increased frequency of events including heat waves, heavy precipitation and intense tropical cyclone activity. Accordingly, climate policy has identified human interference with the climate, and the need for mitigation measures (Klein et al. 2003; Tol 2005). The focus on human interference with the climate system is consistent with the scientific agenda that supports the logic of mitigation, based on the presumption of a causal relationship between human activities and increased concentrations of greenhouse gases in the atmosphere, resulting in climate change with predominantly negative consequences for society. In turn, this mitigation imperative results in a bias against adaptation (Pielke, 2005). 


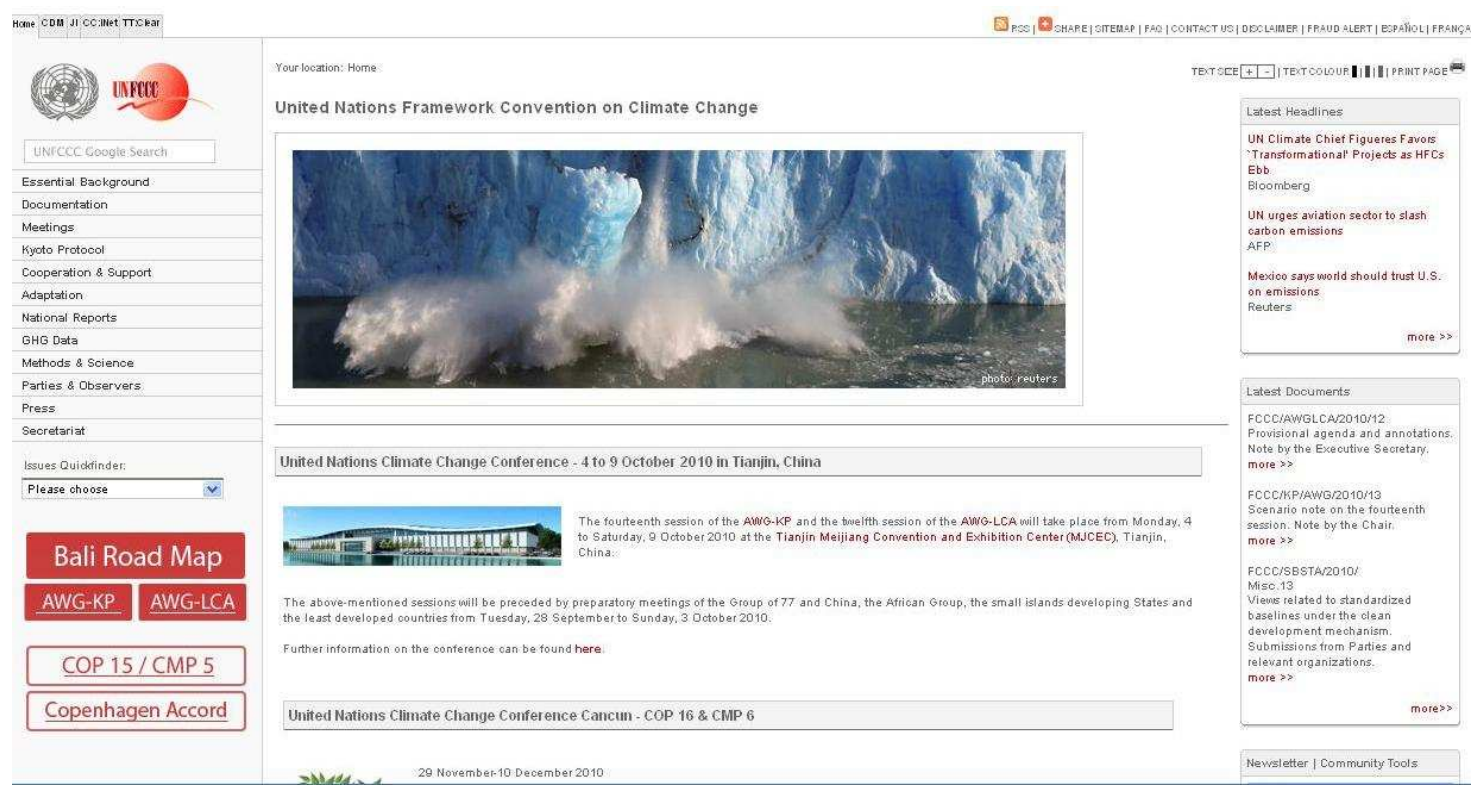

Fig. 2: United Nations Framework Convention on Climate Change website http://unfccc.int/

The UNFCCC provides an overall framework for intergovernmental efforts to control climate change. In the preamble to the UNFCCC, the contracting parties articulate their concern "that human activities have been substantially increasing the atmospheric concentrations of greenhouse gases", and that this will lead to additional warming of the earth's surface and atmosphere. This may adversely affect natural ecosystems and humankind, so the ultimate objective of the Convention (Article 2) is to:

...achieve stabilization of greenhouse gas concentrations in the atmosphere at a level that would prevent dangerous anthropogenic interference with the climate system. Such a level should be achieved within a time frame sufficient to allow ecosystems to adapt naturally to climate change, to ensure that food production is not threatened and to enable economic development to proceed in a sustainable manner (UNFCCC, Article 2).

These formulations embrace the notion that human interference with the climate may result in a situation in which ecosystems can no longer adapt naturally, which in turn will threaten human food supply, welfare and economic growth. From the preamble and the overall objective of the UN Convention, it is clear that the concern expressed about the adverse effects of climate change exclusively concern human survival and welfare.

\section{Environmental protection: do the motives really matter?}

The two Conventions draw on different kinds of values in their motives for biodiversity conservation and climate change mitigation. The UNFCCC stresses the threat of climate change to lifesustaining functions of ecosystems and economic development. This is a clear expression of resourcism, which protects the utilities humans gain from natural resources. The decisive criterion for tolerable climate change is, accordingly, whether or not this change is considered harmless or dangerous to humans.

The CBD, however, articulates both the intrinsic value and a range of instrumental values of biodiversity, including aesthetic and recreational values. One might say that this way of justifying biodiversity conservation is redundant. If biodiversity has intrinsic value, no further justification for its protection is needed. Likewise, if rich biodiversity is considered essential to human survival, humans should protect it irrespective of any inherent worth it may have. Accordingly, a question that comes to mind is whether the motives for environmental protection really matter as long as the arguments are convincing and result in tangible measures.

The wide range of values articulated in the preamble to the CBD most likely stems from the variety of interests that constitute the basis of the Convention. The various cited arguments, motives and values, however, do not always match up, and some even counteract each other. In environmental politics, three categories of arguments are frequently used, corresponding to the categories of instrumental and intrinsic values - aesthetic arguments (beauty of nature and natural scenery), utility arguments (nature as resource for human survival and welfare), and the argument that nature has intrinsic worth. These can be used in 
combination, and even confused, for example between aesthetic and intrinsic value (Soper 1995: $251 \mathrm{ff}$; Uggla 2010). However, it is not self-evident that these different arguments and values should harmonize. References to the beauty of nature imply that specific sights and species considered beautiful or impressive deserve protection, whereas references to intrinsic value also include the protection of places and species considered ugly or even repulsive to humans (Soper 1995: 255; cf. Foale and Macintyre 2005: 13).

Some argue that it is necessary to advocate the intrinsic value of biodiversity to ensure its protection, and use the acknowledgement of this principle to criticize actions based on other values. In particular, utility resulting in the monetization of ecosystem services (Justus et al. 2009: 187). In some instances, these different standpoints - intrinsic versus utility values - have polarized debates over biodiversity protection. While some argue that the concept of nature's intrinsic value is needed to free humans from narrow anthropocentrism, others argue that the intrinsic value concept is useless in decision-making and policy processes aimed at biodiversity protection, because policy-making and decisions and action for biodiversity protection necessarily involve stakeholder interests and prioritization (Justus et al. 2009; Norton 2000; cf. Zisenis 2009). This kind of political negotiation is obvious in the discussion of indigenous peoples' rights and biodiversity conservation in protected areas (see, for example, Schmidt and Peterson 2009; Colchester 2004). Furthermore, in most cases it is various individual components of biodiversity that are valued and negotiated, not biodiversity as such. When discussing intrinsic value in policy-making, this value is frequently attributed to nature, ecosystems, or to various life forms, indicating that the concept of biological diversity as a separate category is difficult to deal with (Uggla 2010). Thus, the intrinsic value of biodiversity, if taken seriously, is an unwieldy concept of limited use in policy-making and biodiversity conservation. It is, however, an indication of an alternate approach to nature by the scientific community that is more obviously aligned with the conservation movement than its engagement with climate change.

\section{Constructions of 'the natural'}

The concern for climate change and biodiversity loss caused by human activity has resulted in international regulation and extensive policies to control greenhouse gas emissions and to protect endangered species, habitats and ecosystems. In this endeavor, both the UNFCCC and the CBD include the concept of "the natural" to point out what is worth protecting.

\section{Climate variability and climate change}

The IPCC and UNFCCC each define climate change slightly differently. The IPCC defines it as "any change in climate over time, whether due to natural variability or as a result of human activity" (IPCC 2007: 871). The UNFCCC explicitly defines climate change as "change of climate which is attributed directly or indirectly to human activity that alters the composition of the global atmosphere and which is in addition to natural climate variability observed over comparable time periods" (Article 1.2). The UNFCCC stresses the distinction between climate variability, which is considered to be a natural phenomenon, and climate change, which is associated with human interference. The IPCC, however, has a more inclusive definition. Despite this difference, both definitions make a distinction between natural variability and changes due to human activities.

The ultimate objective of the UN Convention is to achieve "stabilization of greenhouse gas concentrations in the atmosphere at a level that would prevent dangerous anthropogenic interference with the climate system" (Article 2). This formulation is central and yet problematic. First, it implies a distinct dividing line between dangerous and harmless interference with the climate system. Although present natural climate variation may negatively affect human welfare, it is presumed that ecosystems can cope with such variation and naturally adapt to it, whereas anthropogenic climate change threatens this dynamic equilibrium (cf. Swyngedouw 2007: 18). This presumption implies that human knowledge is "sophisticated enough to reveal the limits of nature, thus permitting us to exploit resources safely up to that limit" (Hajer and Fischer 1999: 5). Second, it conceals regional differences and the intricate intertwining of the matter with issues such as climate adaptation, vulnerability and social change (Pielke, 2005). The focus on human interference with the climate system is consistent with the scientific agenda that supports the logic of the mitigation imperative, based on the presumption of a causal relationship between human activities and increased concentrations of greenhouse gases in the atmosphere, ultimately resulting in climate change with predominantly negative consequences for society. In turn, this mitigation imperative results in a defusing of adaptation demands (Pielke, 2005).

Furthermore, in compliance with a strict interpretation of the UNFCCC, only adaptation measures to human-induced climate change should obtain financial support (Verheyen, 2002). The expectation of being able to distinguish between human-induced climate change and natural climate variability reflects the Annex II Parties' reluctance to provide financial support for regular development projects. However, the formulation is problematic, since natural climate variability and human-induced climate change cannot possibly be clearly distinguished in practice. Instead, expectations of such a distinction may result in awkward considerations of what can be defined as additional harm and additional costs caused by humaninduced climate change (Pielke, 2005; Verheyen, 2002; Klein, 2003). 
At the same time, a number of COP (Conference of the Parties) decisions seem to recognize the problem of distinguishing between climate variability and climate change, and include considerations of current and future climate change as well as of climate variability. These interpretations of the UN Convention thus pave the way for a more integrative view, in which adaptation measures are seen as embedded in a complex of material and socio-economic circumstances, and mainstreamed in various planning and development projects (Lidskog et al. 2009: 76-77). This approach is consistent with most of the adaptation literature, which stresses that adaptation measures are seldom carried out because of climate change alone, but rather are part of decisions triggered by other social and economic events reflecting wider social changes (see, for example, Burton et al., 2002; Adger et al., 2005; Smit and Wandel, 2006). In societal planning, risk management and endeavors to reduce society's vulnerability to extreme weather, the distinction between climate variability and climate change are unproductive or even detrimental.

\section{The Convention on Biological Diversity}

The CBD includes the natural versus non-natural distinction in the concepts of "in situ conservation", "natural habitat", "natural occurrence", and "alien species". According to the Convention, habitat refers to "the place or type of site where an organism or population naturally occurs" (CBD, Article 2). In situ conservation - the primary approach to biodiversity preservation apart from ex situ conservation refers to maintaining or restoring viable wild populations in their natural surroundings, or, for domesticated and cultivated species, conserving them in the surroundings where they have developed their distinctive properties. Biodiversity conservation obviously concerns both wild species and domesticated species improved by breeding. The CBD also introduces the concept of alien, or non-indigenous, species that represent the opposite to those of natural occurrence.

References to the natural seem to be central to wildlife conservation, though what constitutes "natural" is far from self-evident in this context. First, distinguishing between the natural and non-natural requires a dividing line and a temporal point of reference, i.e. a particular moment that determines when a species is considered natural at a certain location and when it is alien (Hannah et al., 2005: 11; cf. Haila, 1999: 55). The status of the natural is established with reference to particular points in history. Second, according to Article $8 \mathrm{~h}$ of the Convention, alien species that threaten ecosystems, habitats, or species should be controlled or eradicated. This Article introduces another dividing line between species that threaten the current order and acceptance of those that can peacefully co-exist. This distinction is negotiable for several reasons.

For example, definitions of the natural and non-natural, and discussions of which alien species should be accepted, may be strained by the effects of anthropogenic climate change. What constitutes natural flora and fauna in times when vegetation zone boundaries are shifting and so-called invasive species are gaining a foothold due to climate change? In these cases, controlling or eradicating alien invasive species with reference to natural occurrence patterns could mean forcing animals and vegetation to match conditions that no longer exist (Hannah et al. 2005: 11).

Paradoxically, at certain locations and times, alien species may even be considered worthy of protection. A case in point is musk oxen (Ovibos moschatus), which died out in Scandinavia thousands of years ago (Fig.3). After some effort, musk ox were reintroduced into Norway in the 1940s. They found their way to Sweden in the 1970s, and today there is a small and not particularly vigorous herd. This herd is not only tolerated but also receives protection, which seems to have little to do with what is natural, but rather with the affection people feel for this prehistoric animal and the fact that the musk ox is a tourist attraction in the area (Andersson, 2005: 87 ff.; cf. Harrop 1999). Musk oxen are thus accepted and protected because of the simple fact that people like them, not because of their natural occurrence in the area. Ultimately, the natural and aliens are awkward concepts that are difficult to define in a continuously changing world.

The natural also plays a role in biodiversity conservation by its centrality in the conservation movement, stressing the importance of wilderness preservation. For some time, biodiversity conservation has emphasised the creation of protected areas. This Western model of nature conservation-based on the fragmentation concept and the idea that nature is best preserved as wilderness or natural nature, has been exported to the rest of the world. The idea of wilderness as a place devoid of human beings has resulted in removal of native peoples from their land (Colchester 2004; Schelhas 2001). Based on a summary on literature and field studies, Colchester (2004: 147) lists a number of social consequences of this approach: denial of rights to land, disruption of kinship systems, undermining of livelihoods, and forced resettlement. These studies also point out that this approach to conservation can be counterproductive, since the removal of people and dissolution of local communities breaks ties to the natural environment, which may reduce the interest in long-term stewardship and create conflicts between the indigenous people and park managers.

In recent decades, indigenous peoples have struggled for recognition, trying to gain access to the centers of power and to be heard in national and international discussions (Schmidt and Peterson 2009; Schelhas 2001). Today, there are a large number of treaties to protect indigenous peoples' rights. There is, 
however, still need for a change in the field of biodiversity conservation and land management concerning the relationship between dominant societies and indigenous people, and indigenous management and biodiversity conservation; that is, that biodiversity conservation can also be achieved in areas where people live (Schmidt and Peterson 2009: 1464).

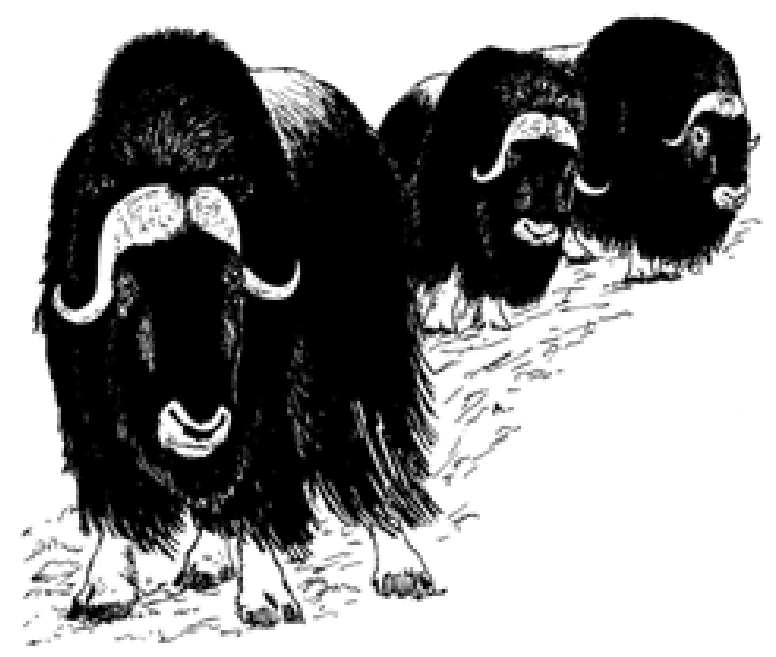

Fig. 3: Musk Oxen (vibos moschatus). Source: Järvzoo AB, www.jarvzoo.se

The emphasis on wilderness and natural nature as a place free from people is strongly asserted in biodiversity conservation discourse, with allusions to Western romanticism. It has resulted in serious impacts on indigenous people's living conditions, while the environmental benefits are questionable.

\section{Concluding remarks}

Biodiversity and climate change regulation help construct nature and culture as separate categories and give rise to the notion that a natural state is worth protecting from human intrusion. In biodiversity and climate change regulation, the concept of "the natural" portrays the idea of untouched nature as desirable, whereas human agency is questionable, representing both destruction and restoration. Human agency threatens the desirable state, for example by interfering with the climate system, intentionally or unintentionally introducing alien invasive species, and fragmenting habitat.

Defining humans as separate from natural systems implies that humans and everything they do, by definition, are non-natural (cf. Oelschlaeger 1991: $296 \mathrm{ff}$.; Keulartz 1999: $83 \mathrm{ff}$.). The notion of human agency is deeply ambiguous, because humans have the power and skill to protect and even recreate natural nature, for example, by restoring or creating wetlands and so-called wildlife corridors, and by establishing protected areas. According to this concept, nature is neutral, whereas human agency is purposeful but Janus-faced, since humans are both destroyers and rescuers. Thus, in climate change and biodiversity policy there is a profound ambiguity in the view of the relationship between humans and their environment. "Natural nature", alluding to romantic ideas of pristine nature devoid of humans, is used to define the desirable. However, it is only when a non-natural human intrusion poses a threat to human existence and well-being that it should be controlled.

The analysis of the UNFCCC and the CBD shows that the concepts of nature and the natural are not stable and neutral, but political concepts that have to be negotiated and filled with meaning according to particular circumstances. The intention behind using these concepts in environmental regulations, to protect the environment and natural resources, is certainly positive. The inclusion of the concepts themselves, however, is dubious for at least four reasons: it may result in futile boundary-setting between humans and nature; it may be counterproductive to environmental protection; it assigns responsibility in a narrow way; and it provides an artificial dichotomy between humans and "pristine" nature.

By treating humans and nature as inter-related, discussions of environmental protection and social justice could focus on how to reduce human vulnerability and accomplish sustainable living conditions, instead of being caught in futile negotiations around how to define and distinguish natural and human impacts. 


\section{References}

Adger, N., N. Arnell and E. Tompkins. 2005. Successful adaptation to climate change across scales. Global Environmental Change: Human and Policy Dimensions 15 (2): 77-86.

Adger, N. 2006. Vulnerability. Global Environmental Change 16 (3): 268-281.

Andersson, P. 2005. Bevara alla arter: regel eller undantag. In Bevara arter till - vilket pris?, pp. 83-94, edited by B. Johansson. Stockholm: Formas.

Binimelis, R., I. Monterosso and B. Rodríguez-Labajosx 2007. A social analysis of the bioinvasions of Dreissena polymorpha in Spain and Hydrilla vertyicillata in Guatemala. Environmental Management 40 (4): 555-566.

Bradley, B. 2006. Two concepts of intrinsic value. Ethical Theory Moral Practice 9 (2): 111-130.

Burton I., S. Huq, B. Lim, O. Pilifosova and E.L. Schipper. 2002. From impacts assessment to adaptation priorities: the shaping of adaptation policy. Climate Policy 2 (2-3): 145-159.

CBD and UNEP 2004. The Convention on Biological Diversity. From conception to implementation. CBD News Special Edition, Montreal, Secretariat of the Convention on Biological Diversity.

CBD 2007. The International Day for Biological Diversity: Biodiversity and climate change, 22 May 2007. http://www.cbd.int/ibd/2007/. Cited 7 July 2008.

Colchester, M. 2004. Conservation policy and indigenous peoples. Environmental Science and Policy 7 (3): 145-153.

Edwards, P.N. 2001. Representing the global atmosphere: computer models, data, and knowledge about climate change. In Changing the atmosphere, pp. 31-65, edited by C. Miller and P. Edwards. Cambridge, MA: MIT Press.

Edwards, P.N. and S.H. Schneider 2001. Self-governance and peer review in science-for-policy: the case of the IPCC Second Assessment Report. In Changing the atmosphere, pp. 219-246, edited by C. Miller and P. Edwards. Cambridge, MA: MIT Press.

Egri, C. 1999. Nature in spiritual traditions: social and cultural implications for environmental change. In Living with nature: environmental politics as cultural discourse, pp. 58-80, edited by F. Fischer and M. Hajer. Oxford: Oxford University Press.

Emmenegger, S. and A. Tschentscher 1994. Taking nature's rights seriously: the long way to biocentrism in environmental law. GIELR 6 (3): 546-592.

Escobar, A. 1998. Whose Knowledge, Whose nature? Biodiversity, Conservation and the Political Ecology of Social Movements. Journal of Political Ecology 5: 53-82.

Evans, J. 2007. The spatial politics of conservation planning. In The sustainable development paradox, pp. 238-265, edited by R. Krueger and D. Gibbs. New York: Guilford Press.

Faarlund, N. 1993. A way home. In Wisdom in the open air, pp. 155-175, edited by P. Reed and D. Rothenberg. Minneapolis: University of Minnesota Press.

Farnham, T. 2007. Saving nature's legacy: origins of the idea of biological diversity. London: Yale University Press.

Foale, S. and M. Macintyre 2005. Green Fantasies: Photographic representations of biodiversity and ecoturism in Western Pacific. Journal of Political Ecology 12: 1-21.

Gandy, M. 2002. Concrete and Clay. Cambridge, MA: MIT Press.

Gieryn, T. 1999. Cultural boundaries of science: credibility on the line. Chicago: University of Chicago Press.

Glowka, L., F. Burhenne-Guilmin and H. Synge 1994. A Guide to the Convention on Biological Diversity. The World Conservation Union. Cambridge, UK: Environmental Policy and Law Paper No. 30, Cambridge.

Haila, Y. 1999. The North as/and the other: ecology, domination and solidarity. In Living with nature: environmental politics as cultural discourse, pp. 42-57, edited by F. Fischer and M. Hajer. Oxford: Oxford University Press.

Hajer, M. and F. Fischer 1999. Beyond global discourse: the rediscovery of culture in environmental politics. In Living with nature: environmental politics as cultural discourse, pp. 1-20, edited by F. Fischer and M. Hajer. Oxford: Oxford University Press.

Hannah, L., T. Lovejoy and S. Schneider 2005. Biodiversity and climate change in context. In Climate change and biodiversity, pp. 3-14, edited by T. Lovejoy and L. Hannah. New Haven: Yale University Press. 
Harrop, S. 1999. Conservation regulation: a backward step for biodiversity? Biodiversity and Conservation 8 (5): $679-707$.

Hay, P. 2002. Main currents in Western environmental thought. Bloomington: Indiana University Press.

Holder, J. and M. Lee 2007. Environmental, protection law and policy. Cambridge, UK: Cambridge University Press.

IPCC 1998. Principles Governing IPCC Work. Approved at the Fourteenth Session (Vienna, 1-3 October 1998) on 1 October 1998, amended at the 21st Session (Vienna, 3 and 6-7 November 2003) and at the 25th Session (Mauritius, 26-28 April 2006). http://www.ipcc.ch/about/how-the-ipcc-is-organized.htm. Cited 25 June 2008.

IPCC 2007. Climate Change 2007. Working Group II Report: Impacts, Adaptation and Vulnerability. IPCC Fourth Assessment Report (AR4). Geneva: IPCC.

Justus, J., M. Colyvan, H. Regan and L. Maguire 2009. Buying into conservation: intrinsic versus instrumental value. Trends in Ecology and Evolution 24 (4): 187-191.

Keulartz, J. 1999. Engineering the environment: the politics of nature development. In Living with nature: environmental politics as cultural discourse, pp. 83-102, edited by F. Fischer and M. Hajer. Oxford: Oxford University Press.

Klein, R., L. Schipper and S. Dessai 2003. Integrating mitigation and adaptation into climate and development policy: three research questions. Norwich: Tyndall Centre for Climate Change Research. Tyndall Centre, Working Paper No 40.

Krishnamurthy, K. 2003. Textbook of biodiversity. Enfield, UK: Science Publishers.

Latour, B. 1993. We have never been modern. Cambridge, MA: Harvard University Press.

Levinson, J. 2004. Intrinsic value and the notion of a life. Journal of Aesthetics and Art Criticism 62 (4): 319-329.

Lidskog, R., L. Soneryd and Y. Uggla 2009. Transboundary risk governance. London: Earthscan.

Lovejoy, T. 2005. Conservation with a changing climate. In Climate change and biodiversity, pp. 325-328, edited by T. Lovejoy and L. Hannah. New Haven: Yale University Press.

Lovejoy, T. and L. Hannah 2005. Policy responses. In Climate change and biodiversity, p. 373, edited by T. Lovejoy and L. Hannah. New Haven: Yale University Press.

MacGrath, C. 2007. Mother nature's restless sons. The New York Times, September 16, 2007.

Macnagthen, P. and J. Urry 1998 Contested natures. London: Sage.

Merchant, C. 2003. Reinventing Eden: the fate of nature in Western culture. London: Routledge.

Miller, C. and P. Edwards 2001. The globalizaion of climate science and climate politics. In Changing the atmosphere, pp. 1-30, edited by C. Miller and P. Edwards. Cambridge, MA: The MIT Press.

Newton, T. 2007. Nature and sociology. New York: Routledge.

Norton, B. 2000. Biodiversity and environmental values: in search of a universal earth ethic. Biodiversity and Conservation 9 (8): 1029-1044.

Oelschlaeger, M. 1991. The idea of wilderness. New Haven: Yale University Press.

Pattberg, P. 2007. Conquest, domination and control: Europe's mastery of nature in historic perspective. Journal of Political Ecology 14: 1-9.

Pielke, R.A.Jr. 2005 Misdefining "climate change": consequences for science and action. Environmental Science and Policy 8 (6): 548-561.

Porter, G., B.J. Welsh and Chasek P. 2000. Global environmental politics. Oxford: Westview Press.

Rehbinder, E. 2002. Obstacles to national implementation of the Convention on Biological Diversity. In Fågelperspektiv på rättsordningen: vänbok till Staffan Westerlund, pp. 375-385, edited by E. Basse, J. Ebbesson and G. Michanec. Uppsala: Istius.

Rientjes, S. 2002. Making nature conservation modern: an analysis of developments in nature conservation policy in relation to macro-social changes - the Netherlands as a case study. Journal of Environmental Policy and Planning 4 (1): 1-21

Secretariat of the Convention on Biological Diversity 2005. Handbook of the Convention on Biological Diversity including its Cartagena Protocol on Biosafety, 3rd ed. Montreal: UNEP.

Schelhas, J. 2001. The USA National Parks in international perspective: have we learned the wrong lesson? Environmental Conservation 28 (4): 300-304. 
Schmidt, P.M. and M.J. Peterson 2009. Biodiversity conservation and indigenous land management in the era of self-determination. Conservation Biology 23 (6): 1458-1466.

Smit B, Wandel J. 2006. Adaptation, adaptive capacity and vulnerability. Global Environmental Change 16 (3): 282-292.

Soper, K. 1995. What is nature? Cambridge: Blackwell.

Swyngedouw, E. 2007. Impossible 'sustainability' and the postpolitical condition. In The sustainable development paradox, pp. 13-40. Edited by R. Krueger and D. Gibbs. New York: The Guilford Press.

Takacs, D. 1996. The idea of biodiversity: philosophies of paradise. Baltimore: Johns Hopkins University Press.

Tol, R. 2005. Adaptation and mitigation: trade-offs in substance and methods. Environmental Science and Policy 8 (6): 572-578.

Tuomivaara, S. 2009. What are the animals needed for in early sociological texts? In Investigation human/animal relations in science, culture and work, pp.44-55, edited by T. Holmberg. Uppsala University: Centre for Gender Studies.

Uggla, Y. 2004. Risk and safety analysis in long-term perspective. Futures 36 (5): 549-564.

Uggla, Y. 2010. The value of biological diversity: a travelogue. Journal of Environmental Planning and Management 53 (1): 91-105.

van der Sluijs, J., J. van Eijndhoven, S. Shackley and B. Wynne 1998. Anchoring devices in science for policy: the case of consensus around climate sensitivity. Social Studies of Science 28 (2): 291-323.

Verheyen R. 2002. Adaptation to the impacts of anthropogenic climate change: the international legal framework. Review of European Community \& International Environmental Law 11 (2): 129-143.

von Storch, H. 2009. Climate research and policy advice: scientific and cultural constructions of knowledge. Environmental Science and Policy 12 (7): 741-747.

Zimmerman, M. 2001. The nature of intrinsic value. Lanham: Rowman and Littlefield.

Zisenis, M. 2009. To which extent is the interdisciplinary evaluation approach of the CBD reflected in European and international biodiversity-related regulations? Biodiversity and Conservation 18 (3): 639648. 


\begin{abstract}
This paper treats two highly topical and interconnected environmental issues-climate change and biodiversity-in which the nature-culture divide appears in policy and regulation. The aim is to analyze how "the natural" and concerns for biodiversity and climate change are constructed in applicable regulatory frameworks, and to explore social and environmental consequences of these constructions. The analysis indicates that biodiversity and climate change regulation help construct nature and culture as separate categories and give rise to the notion that the natural state is worth protecting from human intrusion. The notion of human agency, however, is ambiguous because humans are depicted as having the power and skill to protect and even recreate "natural nature". The paper concludes that, although nature and the natural are often used as politically and socially-neutral concepts, the definition of "natural nature" as a place devoid of humans has social as well as environmental consequences.
\end{abstract}

Keywords: biodiversity, climate change, human-nature relations, environmental protection, environmental regulation

\title{
Résumé
}

Cet article traite deux questions interconnectées de l'environnement: changements climatiques et biodiversity.In chaque cas, une fracture nature-culture apparaît dans la politique et la réglementation. L'obiectif est d'analyser comment "naturel" et les préoccupations pour la biodiversité et les changements climatiques sont construits dans des cadres réglementaires applicables, et d'explorer les conséquences sociales et environnementales de ces constructions. L'analyse indique que la biodiversité et la régulation des changements climatiques aider à construire la nature et la culture comme des catégories distinctes. Cela donne lieu à l'idée que l'état naturel est digne d'être protégé contre l'intrusion de l'homme. La notion d'agence de l'homme, cependant, est ambiguë car l'homme est dépeint comme ayant le pouvoir et la compétence pour protéger et même de recréer la «nature naturelle». L'article conclut que, bien que la nature et le naturel sont souvent utilisés comme des concepts neutres, la définition de la «nature naturelle» comme un lieu sans les êtres humains a des conséquences sociales et environnementales.

Mots-clés: biodiversité, changement climatique, les relations homme-nature, protection de l'environnement, la réglementation environnementale

\section{Resumen}

Este artículo aborda dos cuestiones ambientales interconectados: el cambio climático y la biodiversidad. En cada caso, una división entre naturaleza y cultura aparece en la política y la regulación. El objetivo es analizar cómo "lo natural" v la preocupación por la biodiversidad y el cambio climático se construyen en los marcos regulatorios aplicables. También se exploran las consecuencias sociales y ambientales de estas construcciones. El análisis indica que la diversidad biológica y la regulación del cambio climático ayudar a construir la naturaleza y la cultura como categorías separadas. Esto da lugar a la noción de que el estado natural es digno de ser protegido de la intrusión humana. La noción de la acción humana, sin embargo, es ambigua porque los humanos son presentados como tener el poder y habilidad para proteger y volver a crear incluso "natural naturaleza". El artículo concluve que, aunque la naturaleza y lo natural se utilizan a menudo como conceptos neutral, la definición de la "naturaleza natural" como un lugar sin los seres humanos tiene importantes consecuencias sociales y ambientales.

Palabras clave: biodiversidad, cambio climático, las relaciones hombre-naturaleza, la protección del medio ambiente, la regulación ambiental 